\title{
PREDICTION OF THE TRANSOM FLOW REGIME WITH VISCOUS FREE SURFACE COMPUTATIONS
}

\author{
MARINE 2011 \\ AUKE VAN DER PLOEG AND BRAM STARKE \\ Maritime Research Institute Netherlands (MARIN) \\ 6700 AA Wageningen \\ a.v.d.ploeg@marin.nl
}

Key words: Computational Fluid Dynamics, Transom Sterns, Scale Effects.

Summary. A steady free-surface fitting RANS method is used to accurately and efficiently compute the flow near a ship's transom. The chosen block topology is very well suited for the prediction of such flows: viscous free-surface flow solutions have been obtained for all transom flow regimes (from completely dry, partly wetted to completely wetted) and the agreement with available measurements is good. We will show that scale effects on the flow aft of the transom can be significant: they can affect the wave length and wave amplitude aft of the transom, and can even change the transom flow regime from partly wetted to completely dry.

\section{INTRODUCTION}

Ship resistance and propulsion are principal aspects for the fuel efficiency of maritime transport. Modern CFD techniques in principle permit a further improvement of that efficiency by precisely predicting resistance and scale effects. Especially, an accurate prediction of viscous free-surface flows near a ship's transom is important, since this is a prerequisite for the computation of the effect of stern wedges and stern flaps which can be used to improve the ship powering performance ([4]).

A (partly) wetted transom poses additional challenges on a computational method: the details of the free surface and the recirculating flow behind the wetted part of the transom, the transition between the wetted and dry regime along the transom, and the possible occurrence of a spilling breaker when the transom is close to becoming wetted. Scale effects affect the wave length and wave amplitude aft of the transom, but might become even more important when the transom flow regime changes between model and full scale.

In [10] a detailed study of the flow off a 2D transom stern was presented. For dry-transom flow, 'inviscid' computations using our RANS solver showed excellent agreement with nonlinear potential-flow solutions available in the literature. Viscous effects were shown to cause a substantial reduction of the trailing wave length, and a scale effect on that wave length. The transom immersion was systematically increased to investigate the limits of the dry-transom regime. A local vanishing of the longitudinal velocity at the wave surface near the first wave crest was used as an indication of wave breaking. The critical Froude number at which this happens is substantially increased by viscous effects, and much more so for model 
scale than for full scale. Therefore, in a range of transom Froude numbers a smooth flow will occur at full scale, but a spilling breaker just aft of the transom at model scale. It was shown that the width of this range may depend on the hull form (in 3D cases), as it results from two opposing scale effects.

For wetted transom flows, the predictions at model scale in [10] showed good agreement with experimental data for the water level at the transom and the trailing wave system. The transom immersion was systematically decreased to investigate the clearance of the transom. It was shown that at a given transom immersion the clearance is larger at full scale than at model scale. Thus is was shown that there is a range of conditions where the transom is just cleared at full scale, with a spilling breaker downstream, while the flow is still attached to the transom at model scale.

The question is whether such scale effects are similar for 3D ships. Strictly speaking, no direct comparability exists between 2D and 3D since in the 2D computations

1. there is no effect of the waves coming from upstream;

2. there is no decay of the waves as in $3 \mathrm{D}$, so one can expect steeper waves at some distance aft in $2 \mathrm{D}$ computations;

3. there is no effect of the wakes of any upstream appendages or the propulsion;

Therefore in this paper we will present viscous free-surface computations at both model and full scale for three different ships: the KRISO Container Ship (KCS), DTMB model 5415 (M5415) and the VIRTUE Container Ship (VCS). The first two test cases have extensively been used in many international workshops, most recently in the Gothenburg 2010 Workshop on Numerical Ship Hydrodynamics [11]. The last test case has been used in the EU-sponsored VIRTUE project. All three test cases are transom-stern vessels and for all three test cases experimental data at model scale is available. Some characteristics of the ships and the flow conditions are listed in Table 1. In Section 2 we will present our RANS method, with some emphasis on the free-surface treatment and the adopted block topology. In Section 3 we will present results of systematic grid-refinement studies, and comparison with available experimental data, followed by a discussion on the predicted scale effects near the transom in Section 4.

Table 1: Characteristics of the three test cases.

\begin{tabular}{|l|l|l|l|l|l|}
\hline & Rn (model) & Rn (ship) & $\mathrm{L}_{\mathrm{pp}}[\mathrm{m}]$ & Fn & $\mathrm{T}[\mathrm{m}]$ \\
\hline Kriso Container Ship (KCS) & $1.40 \times 10^{7}$ & $2.5 \times 10^{9}$ & 230 & 0.26 & 10.8 \\
\hline DTMB 5415 (M5414) & $1.19 \times 10^{7}$ & $6.5 \times 10^{8}$ & 142 & 0.28 & 6.15 \\
\hline VIRTUE Container Ship (VCS) & $1.85 \times 10^{7}$ & $2.0 \times 10^{9}$ & 246.4 & 0.272 & 12.5 \\
\hline
\end{tabular}



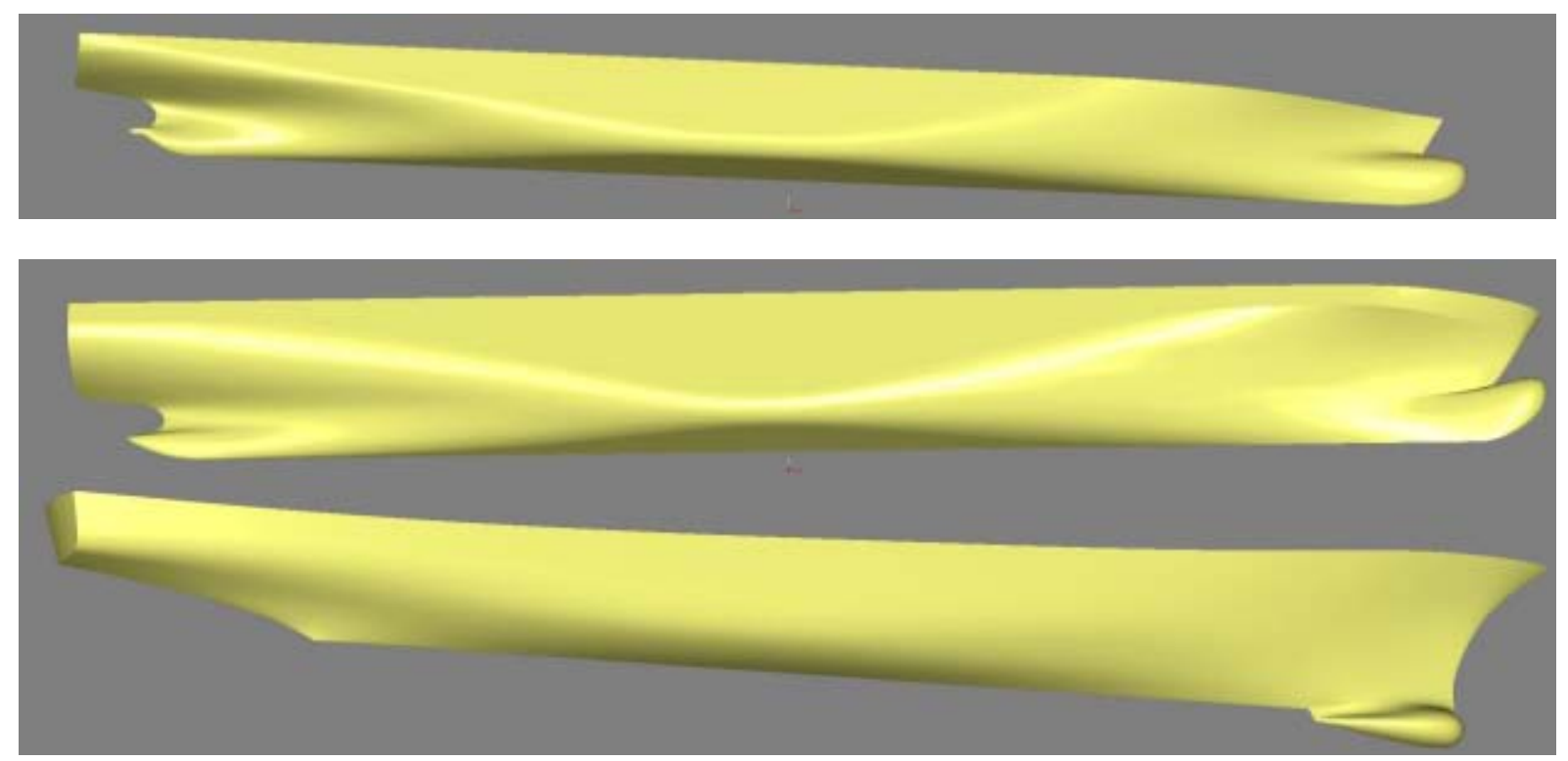

Figure 1: Geometries for the three test cases: top KCS, middle VCS, bottom M5415.

\section{THE COMPUTATIONAL METHOD}

\subsection{RANS solver}

The method used is PARNASSOS, a code developed and used by MARIN and IST [3,7]. It solves the discretised Reynolds-averaged Navier-Stokes (RANS) equations for a steady, 3D incompressible flow around a ship's hull. Various eddy-viscosity turbulence models are available. For the computations for the VCS and the M5415 presented in this paper, the oneequation turbulence model of Menter [6] was used. For the computation for the KCS we also used the two-equation k- $\omega$ SST model by Menter [5]. Both models were extended with a correction for the longitudinal vorticity [2].

The discretisation is of finite-difference type. All terms in the momentum and continuity equations are discretised by second or third-order accurate difference schemes. PARNASSOS can handle body-fitted, generally non-orthogonal HO-type grids, either single or multi-block structured.

For the cases studied here, the inflow boundary is located $0.5 \mathrm{~L}_{\mathrm{pp}}$ in front of the bow, and the outflow boundary was located $1.5 \mathrm{~L}_{\mathrm{pp}}$ behind the transom. Due to symmetry considerations, only the starboard side of the ships are taken into account. The lateral outer boundary is a quarter of a cylinder with axis $y=z=0$ and radius $1.0 \mathrm{~L}_{\mathrm{pp}}$. At this boundary tangential velocities and pressure found from a potential-flow computation are imposed. Since that computation gives good results already for much of the wave pattern, these boundary conditions (although of Dirichlet type) hardly cause any wave reflection.

The momentum and continuity equations are solved in fully coupled form. Therefore, the continuity equation need not be recast in a pressure correction or pressure Poisson equation, but can simply be solved as it is. After discretisation and linearisation, the three momentum equations and the continuity equation give rise to a matrix equation containing $4 * 4$ blocks, 
which is solved using preconditioned GMRES. This fully coupled solution has been found to be robust and quite insensitive to the mesh aspect ratio. This allows solving the discretized equations on extremely contracted grids close to the wall. As a result, wall functions are not necessary, not even at full scale. More details about the solution strategy can be found in [7].

\subsection{Free-Surface treatment}

We have used the 'steady iterative formulation' [1,9] which, contrary to almost all other RANS/FS methods, involves no time-dependent terms; neither in the momentum equations, nor in the free-surface boundary conditions. The problem is solved by an iterative procedure, instead of by time integration. This iteration is based on the use of the "combined free-surface condition":

$$
F n^{2}\left(u \psi_{x}+v \psi_{y}+w \psi_{z}\right)-w=0 \text { at } z=\zeta,
$$

where $\psi$ is the non-dimensional hydrodynamic pressure. This condition is obtained by substituting the wave elevation from the dynamic condition into the kinematic condition. Together with the dynamic condition it describes exactly the same problem as the original set of conditions; but it has the advantage of permitting a successful iterative procedure.

In the present applications, the 'balanced discretisation' derived in [9] has been used, which reduces the numerical damping of the waves to $5^{\text {th }}$ order in the longitudinal step size $\Delta \mathrm{x}$, and the numerical dispersion to $3^{\text {rd }}$ order in the vertical spacing $\Delta \mathrm{z}$. This contributes to a good accuracy of the wave pattern even at a distance from the hull.

\subsection{Grids suited for both dry and wetted transom}

We use a special block topology that can handle both wetted and dry transoms, and even transoms that are partly dry and partly wetted. This topology, illustrated in Fig. 2, consists of four blocks. One block upstream of the transom contains an HO-type grid with a mild stretching towards the bow and the stern in longitudinal direction, and the usual strong contraction in wall-normal direction towards the hull in order to have $y^{+}$-values below 1 near the wall. This upstream block has a non-conformal matching with three blocks downstream of the transom, containing HH-type grids. The grid nodes in the block immediately behind the transom are both contracted towards the symmetry plane and the free surface to get sufficient resolution near the transom, also in vertical direction at a possibly wetted part of the transom.

\subsection{Grid density}

The typical grid density we need for such computations is illustrated for the M5415 in Fig. 2. This grid consists of 3.7 million cells for all four blocks together. In the model-scale computations the block upstream of the transom (indicated in red in Fig. 2), consists of $290 \mathrm{x}$ 120 x 52 cells in the streamwise, wall-normal and girthwise directions, respectively, adding up to a total of $1.8 \mathrm{M}$ cells for this block. For the full-scale computations, the number of cells in the wall-normal direction is increased (in order to keep $\mathrm{y}^{+}$-values below 1), resulting in a total number of 4.2 million at full scale. The block immediately behind the transom (green in Fig. 2), consists of 144 x $99 \times 99=1.4 \mathrm{M}$ cells, and the remaining cells are distributed evenly over the two other blocks. For the other two test cases, similar grid densities are used. 

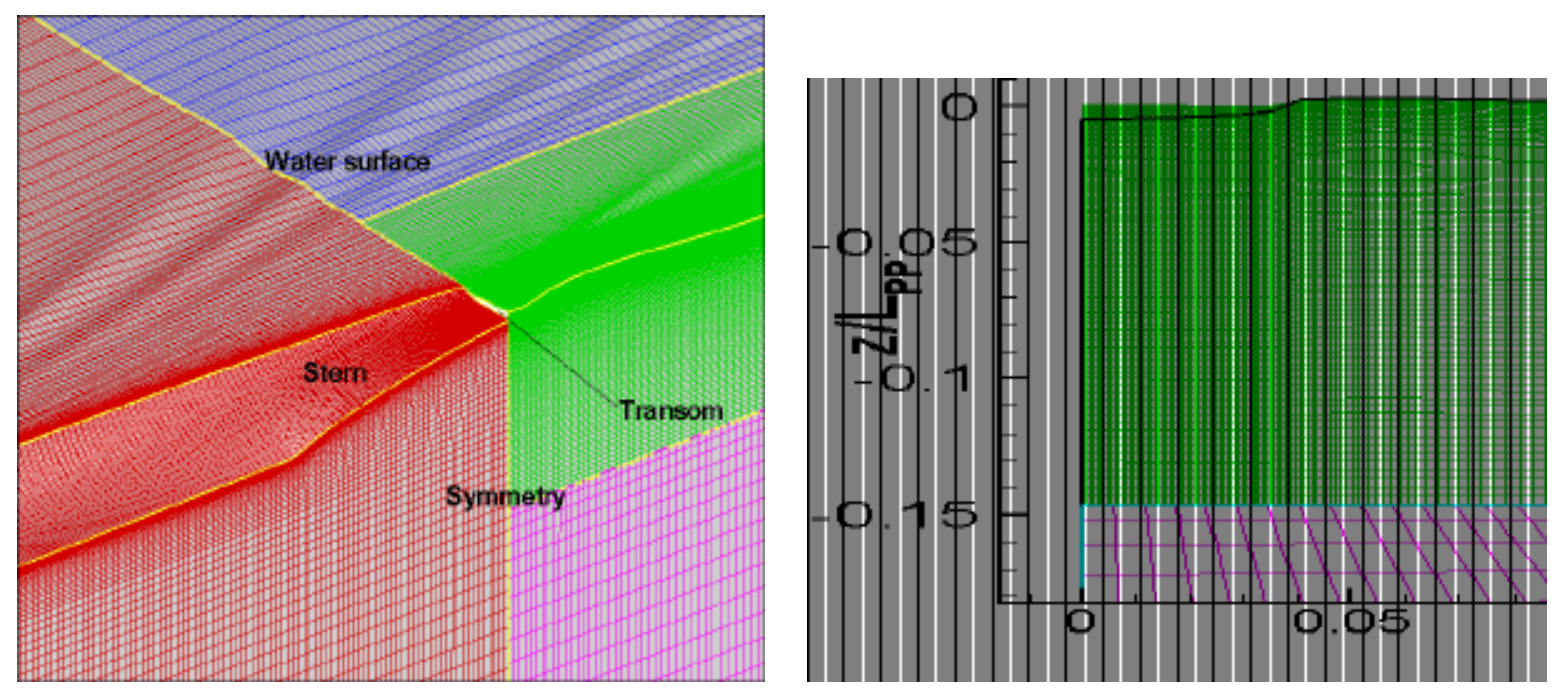

Figure 2: Left: bird's-eye view of the adopted block topology. Right: a cross section of the computational mesh in the three blocks aft of the transom: the black line indicates the transom edge in the upstream block.

\section{GRID DEPENDENCE STUDIES AND COMPARISON WITH EXPERIMENTS}

For all test cases, several grid dependence studies were performed and the grid dependence was shown to be limited, giving good agreement with measured wave heights, wake fields and resistance values $[8,11]$. An example of such a study is shown in Fig. 3, in which both pictures show a comparison between the computed and measured wave patterns for the M5415. The computed wave elevation shown in the picture on the left was obtained using the $3.7 \mathrm{M}$ base grid described above, whereas the picture on the right compares the wave elevation computed on a grid that was refined by a factor of two in the main stream direction. Hence the total number of cells increased to 7.4 million. Even with the wave height multiplied by a factor of five in these figures hardly any difference can be seen between the predicted wave patterns, indicating that the basis grid resolution in the streamwise direction was sufficient. The predicted wave height corresponds well with the measured wave height.

Similar studies have been made for the grid resolution in the other directions, which is illustrated for a wave cut in the bottom picture in Fig. 4. At this longitudinal position the influence of grid refinement is negligible in all three directions, and very reasonable agreement is obtained with the experimental data along most part of the ship, with the exception of details near the bow and the stern. For example, the local wave top near the stern in the measurements near $\mathrm{x}=1.15 \mathrm{~L}_{\mathrm{PP}}$ seems not to be present in the computations. However, for a wave cut slightly closer to the symmetry plane this local peak is present in the computations as well, as is illustrated in the top picture in Fig. 4. Also the height of the computed bow wave at the wave cut $y=0.072 \mathrm{~L}_{\mathrm{PP}}$ is closer to the measured height of this wave a the wave cut $\mathrm{y}=0.082 \mathrm{LPP}$. 

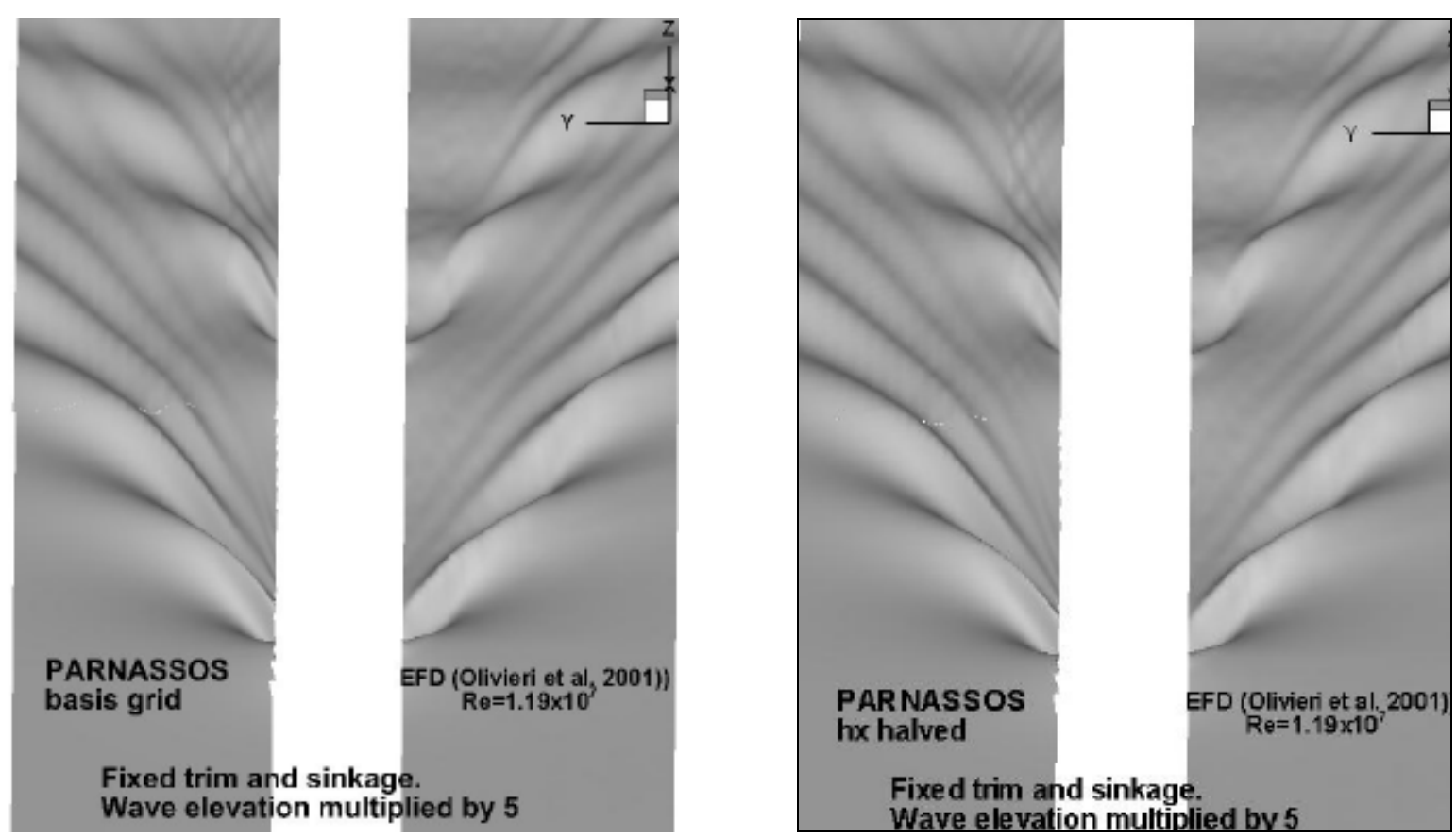

Figure 3: Comparison between the computed and measured wave elevation for the M5415. Left: computed on the base grid. Right: computed on the base grid after halving the cell size in streamwise direction.

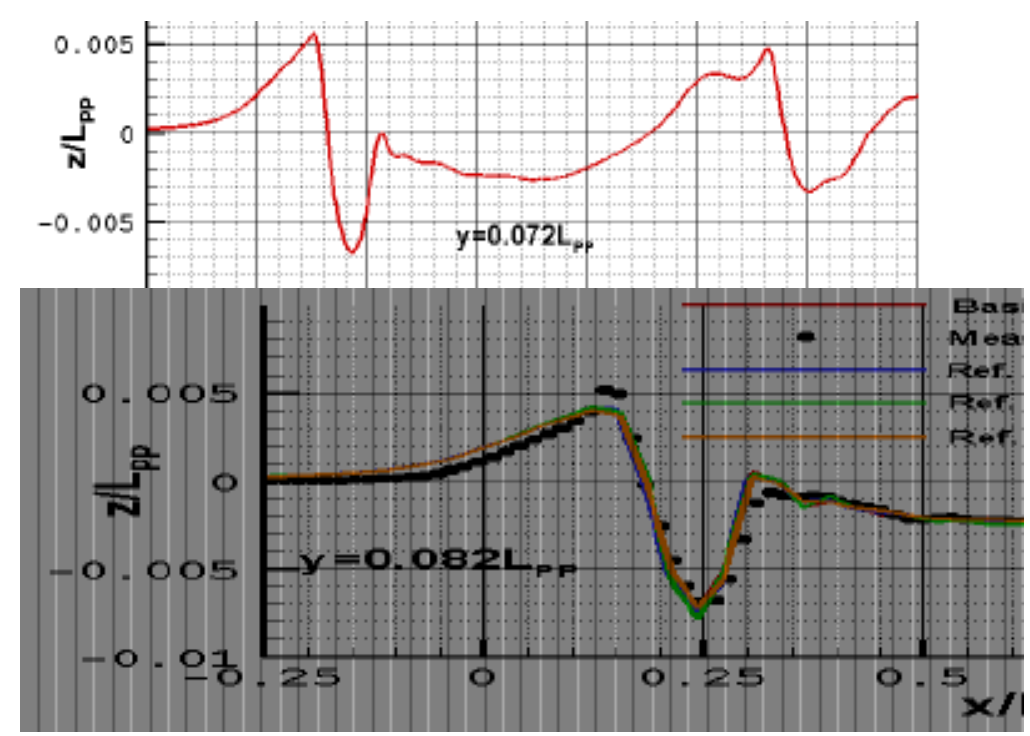

Figure 4: Top: wave elevation along a longitudinal wave cut $y=0.072 \mathrm{~L}_{\mathrm{PP}}$ for the M5415. Bottom: The influence of grid refinement in successive directions and comparison with experiments at a wave cut $y=0.082 \mathrm{~L}_{\mathrm{PP}}$.

For the VCS, wave height measurements behind the transom of the model were obtained using a dedicated test rig supporting a set of line lasers in combination with a water spray curtain behind the transom that was installed on the towing carriage [8]. A comparison 


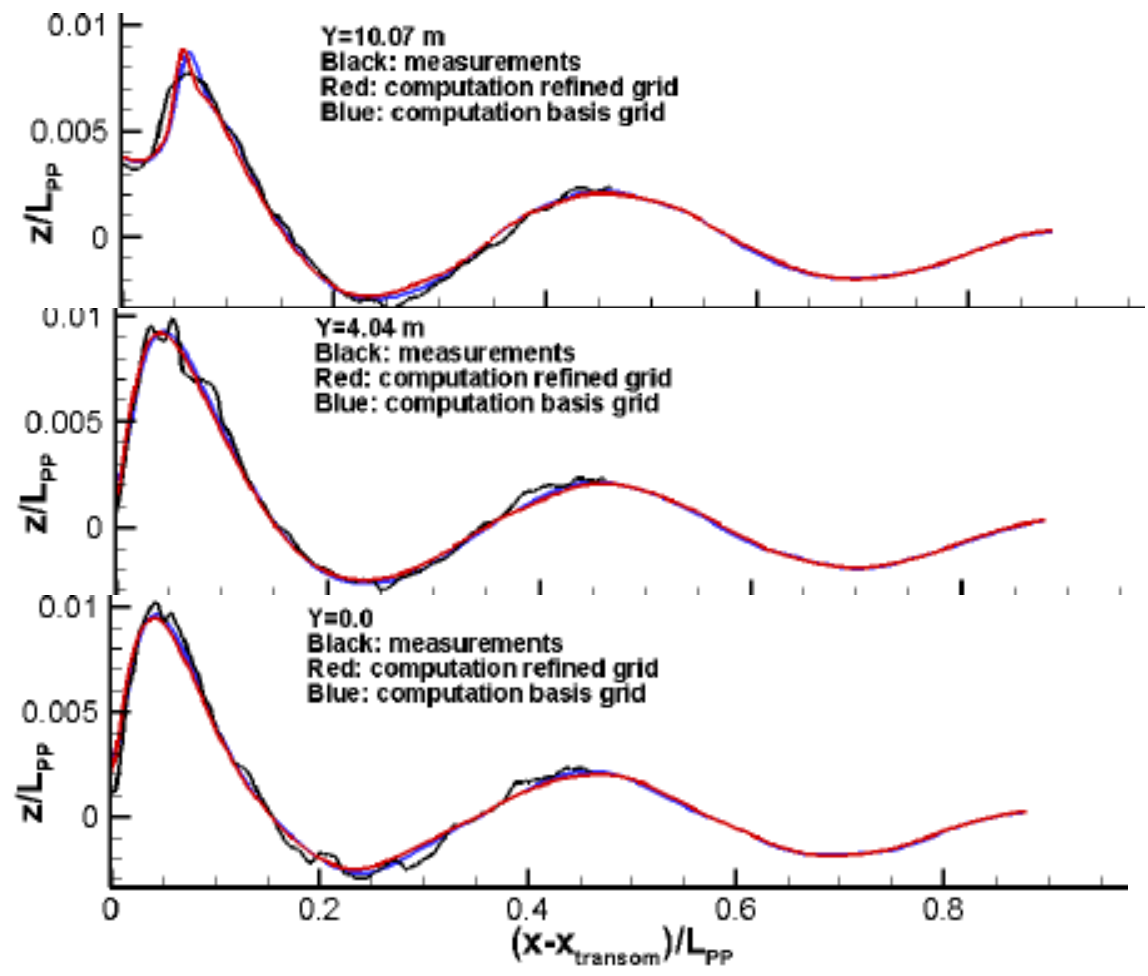

Figure 5. Computed and measured wave elevations at three longitudinal positions aft of the transom of the VCS.

between measured and computed wave heights aft of the transom along three wavecuts is shown in Fig. 5. The agreement between computations and measurements is excellent, for the wave amplitude as well as for the wave length. Two sets of computational results are shown; the blue lines in Fig. 5 show results computed on the base grid, the red lines show results computed on a grid in which the mesh size in main stream direction was halved. As the blue lines and the red lines are practically indistinguishable, the grid dependence in the computed wave height is negligible.

\section{SCALE EFFECTS ON THE FREE SURFACE}

It is well known that scale effects on the free surface are mainly restricted to the stern wave system. Along the bow and most part of the hull of slender ships the boundary layer is thin and does not affect the pressure distribution on the hull. Therefore, the wave patterns generated at model and full scale (and even for non-linear potential flow solutions) are similar, the very basis of Froude's hypothesis. Near the stern however the boundary can grow considerably (of course depending on hull form and flow conditions) thus reducing the pressure rise towards the stern and the velocity distribution in the wake. This in its turn affects the wave generation and propagation aft of the transom. All this is illustrated in Fig. 6 for the VCS. The entire bow-wave system and wave pattern along the hull are equivalent at model and at full scale. Only in the stern-wave system aft of the transom noticeable differences can 

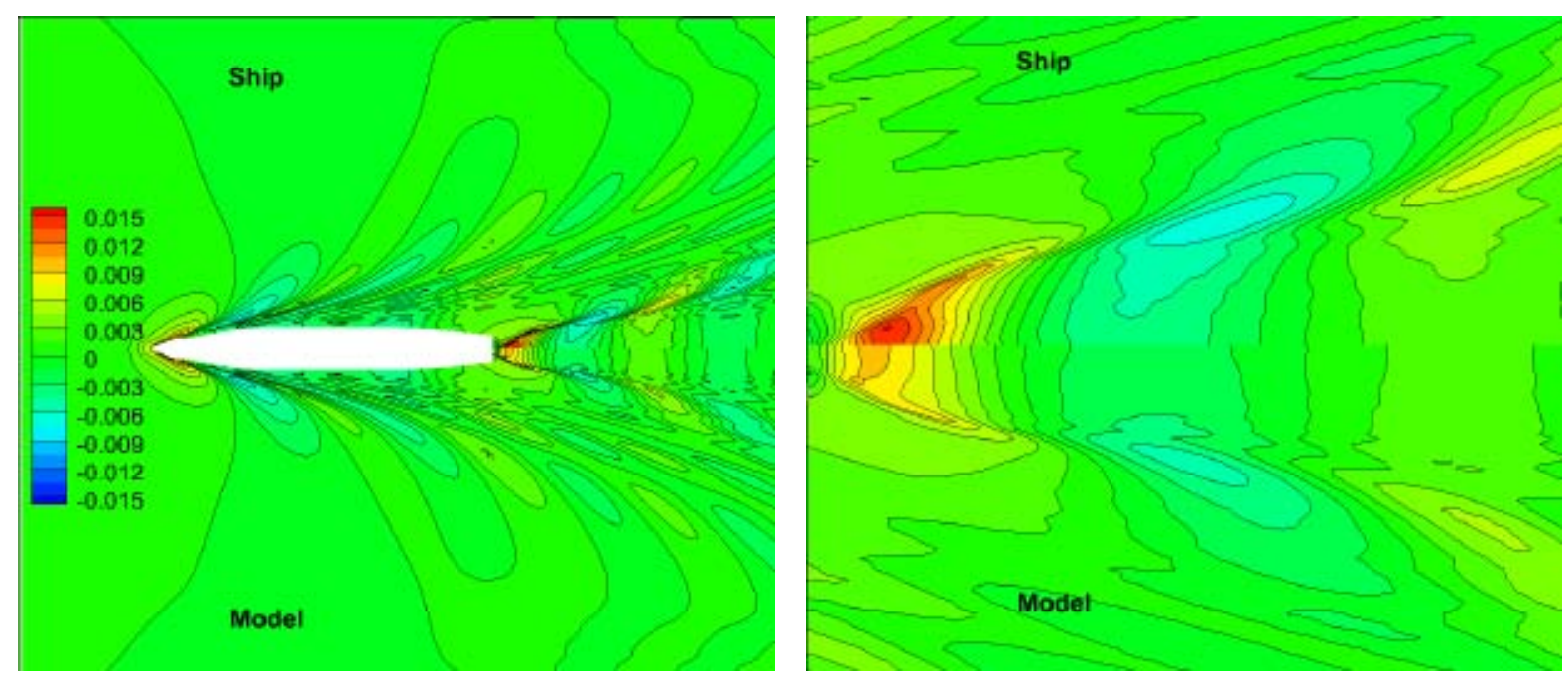

Figure 6: Scale effects in the wave elevation for the VCS. Right: a close-up of the transom-region.

be found. There viscous effects, which are larger at model scale than at full scale, result in a reduction of the wave elevation and, although not that clear from these graphs, a reduction of the transverse wave length aft of the transom. This is similar to what we have found in the 2D study discussed in Section 1. An illustration of the scale effect on the flow off the transom for all three test cases is given in Fig. 7. This figure shows the wave elevation aft of the transom with the predicted axial velocity in main stream direction projected on the free surface as colored contours. Black colors indicate regions with flow reversal. Fig. 8 shows a more detailed study of the scale effect along a longitudinal wave cut along the symmetry plane, and comparison with experimental (model scale) data. Below we discuss the scale effects shown in Fig. 7-8 for each case.

\section{$K C S$}

At model scale the flow is characterised by a region with low axial velocities in the top of the wave crest around the centreline. This indicates that in reality a spilling breaker might occur, or that the flow is close to forming a spilling breaker. At full scale, however, the top of the first wave crest is located further downstream, while the velocity reduction towards the top of the wave crest is less strong than at model scale. Therefore, the flow at full scale is further away from forming a spilling breaker than at model scale. In both conditions the transom is dry.

$V C S$

At model scale the transom of the VCS is partly wetted, and in [11] it has been shown that the width of this region compares well with the experimental data. At full scale, however, our computations indicate that the transom is completely dry, thus showing a scale effect on the transom regime. In addition, in Fig. 8 we see a clear increase (about 40\%) of the wave amplitude from model to full scale and the top of the first wave crest behind the transom shifts slightly further downstream. 


\section{M5415}

The model of the M5415 has a completely wetted transom. At full scale the transom is predicted to be wetted as well, but the water level at the transom decreases from model to full scale. This is in agreement with the conclusions of our 2D study of the wetted regime, where the higher shear forces that act on the recirculation region at full scale result in a reduction of the pressure inside this region, and thus an increased clearance of the transom, compared to model scale. These effects can be seen more clearly in Fig. 9, which shows the scale effects in the pressure distribution in a cross section at the transom.

\section{CONCLUSIONS}

With the free surface RANS method described in this paper, the viscous flow near the transom can be computed for several transom flow regimes, from completely dry to (partly) wetted. The steady iterative approach as used in PARNASSOS is very efficient to compute the free surface and the block structure as described in this paper is well suited to compute the viscous flow including the free surface accurately near the transom, since it enables local grid refinement near the wetted part of the transom.

Compared to many surface capturing methods, the surface fitting approach used in PARNASSOS has as advantage that the free surface is sharp: it is not 'smeared out' in the direction normal to the surface across several cells. The 'balanced discretisation' derived in [9] has been used, which reduces the numerical damping of the waves to $5^{\text {th }}$ order which further enhances the accuracy of the computations. We have shown that for the three test cases the grid dependence in the results is limited and we get good agreement with modelscale measurements. Unfortunately, experimental data for full scale is not available. However, as mentioned earlier, we found excellent agreement between 'inviscid' computations using our RANS solver and nonlinear potential-flow solutions for the 2D test case mentioned in Section 1. Together with the similarity between model-scale computations and measurements this sustains the confidence in the computed scale effects:

- For all three test cases, scale effects on the free surface are mainly restricted to the stern wave system.

- For the test case for which the transom at model scale is dry, similar scale effects were observed as for the 2D test case described in [10]: the waves behind the transom become steeper, the wavelength decreases and the velocity in the top of the first wave behind the transom decreases when going from full scale to model scale. However, an additional scale effect for this $3 \mathrm{D}$ test case which was not observed for the 2D test case is the increase in wave amplitude from model to full scale.

- For the test case with a partly wetted transom at model scale, significant scale effects were observed: at full scale the transom is completely dry, and the wave amplitude increases significantly from model to full scale.

- The test case in which the transom is completely wetted at model scale showed a decrease of the water level at the transom from model to full scale. 


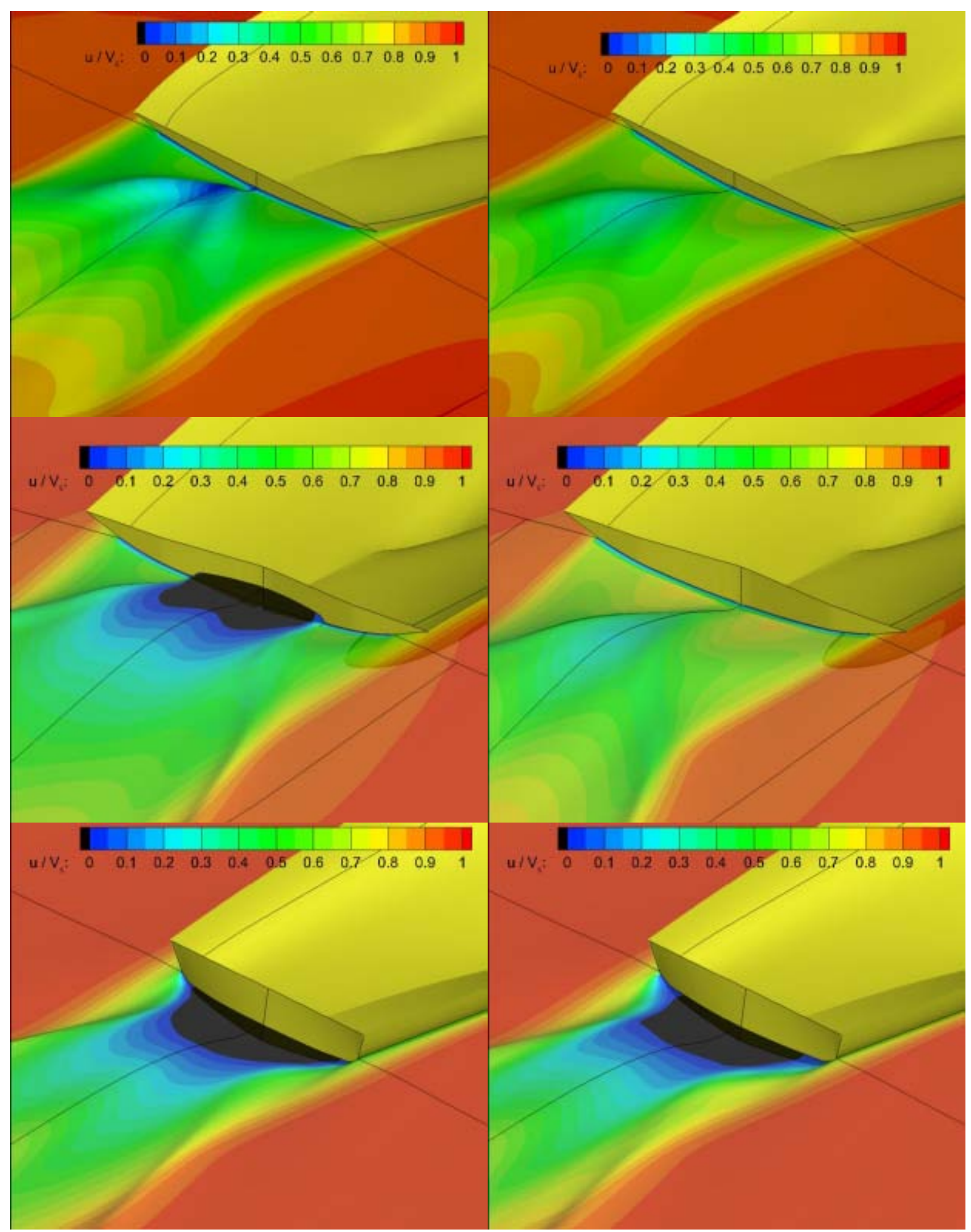

Figure 7: Scale effects on the flow off the transom, model scale results on the left, full scale results on the right; KCS (top): dry at model scale, dry at full scale; VCS (middle): partly wetted at model scale, dry at full scale; M5415 (bottom): wetted at model scale, wetted at full scale. 

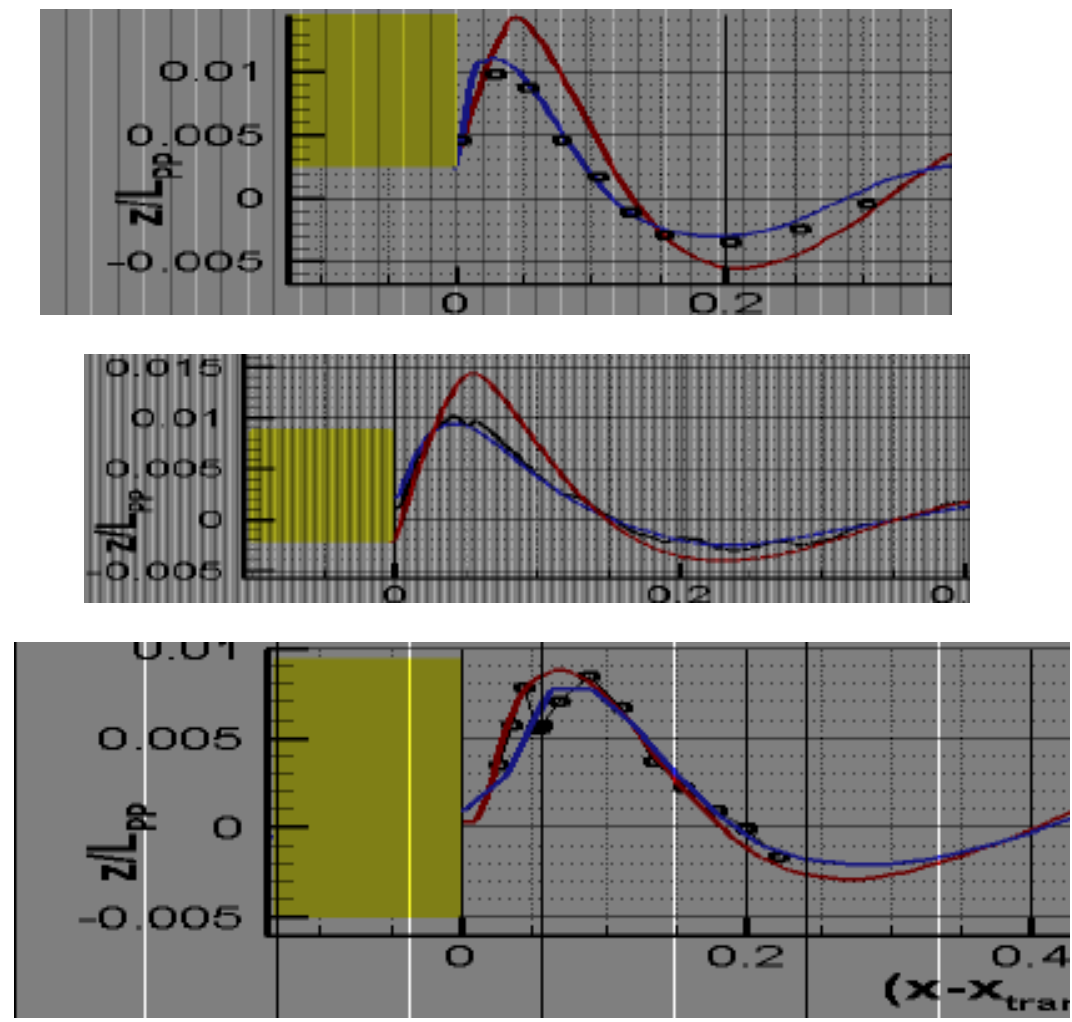

Figure 8: Scale effects at the wave cut in the symmetry plane aft of the transom for the KCS (top), VCS (middle) and the M5415 (bottom). Black: measurements model. Blue: computation model. Red: computation ship.

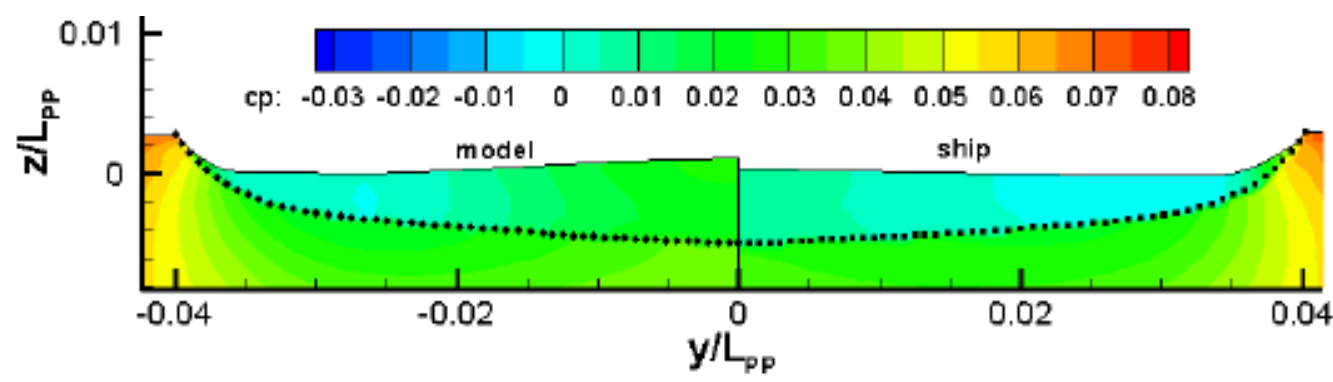

Figure 9: Scale effects in the pressure coefficient in a cross section near the transom of the M5415. The black dots indicate grid points on the transom edge. 


\section{REFERENCES}

[1] Van Brummelen, E.H., Raven, H.C. and Koren, B., "Efficient numerical solution of steady free-surface Navier-Stokes flow", Jnl. Computational Physics, Vol. 174, pp. 120-137, (2001).

[2] Dacles-Mariani, J., Zilliac, G.G., Chow, J.S., and Bradshaw, P., "Numerical/ experimental study of a wingtip vortex in the near field", AIAA Jnl, Vol. 33-9, pp. 1561-1568, (1995).

[3] Hoekstra, M., "Numerical simulation of ship stern flows with a space-marching Navier Stokes method", Thesis, Technical University of Delft, (October 1999).

[4] Karafiath G., Cusanelli D. and Cheng, W.L. 'Stern Wedges and Stern Flaps for Improved Powering - U.S. Navy Experience.' Sname Annual Meeting, Baltimore, (1999).

[5] Menter, F.R., "Two-equation eddy-viscosity turbulence models for engineering applications", AIAA Journal, Vol. 32, pp. 1598-1605, (August 1994).

[6] Menter, "Eddy viscosity transport equations and their relation to the $k-\varepsilon$ model", Jnl Fluid Eng. Vol. 119, pp. 876-884, (1997).

[7] Van der Ploeg, A., Hoekstra, M., and Eça, L., "Combining accuracy and efficiency with robustness in ship stern flow computation", 23rd Symp. Naval Hydrodynamics, Val de Reuil, (France, 2000).

[8] Van der Ploeg, A., Chao, K., Marzi, J., Wackers, J., "Computation of Scale Effects in Free-Surface Flows near a Ship's Transom" $13^{\text {th }}$ Numerical Towing Tank Symposium, Duisburg, Germany, (October, 2010).

[9] Raven, H.C., Van der Ploeg, A. and Starke, A.R., "Computation of free-surface viscous flows at model and full scale by a steady iterative approach", $25^{\text {th }}$ Symposium on Naval Hydrodynamics, St. John's, Newfoundland, CANADA, (August 2004).

[10] Starke, A.R., Raven, H.C., and Van der Ploeg, A., "Computation of transom-stern flows using a steady free-surface fitting RANS method", $9^{\text {th }}$ Int. Conference on Numerical Ship Hydrodynamics, Ann Arbor, Michigan, (August 5-8, 2007).

[11] Starke, A.R., Van der Ploeg, A. and Raven, H.C., "Viscous free surface flow computations for self-propulsion conditions using PARNASSOS", CFD workshop Gothenburg (2010). 